\title{
Precise Localization of Sentinel Lymph Nodes and Estimation of Their Depth Using a Prototype Intraoperative Mini $\gamma$-Camera in Patients with Breast Cancer
}

\author{
Carole Mathelin ${ }^{1}$, Samuel Salvador ${ }^{2}$, Daniel Huss ${ }^{2}$, and Jean-Louis Guyonnet ${ }^{2}$ \\ ${ }^{I}$ Service de Gynécologie-Obstétrique, Hôpital Civil, CHRU, Strasbourg, France; and ${ }^{2}$ Institut Pluridisciplinaire Hubert Curien, UMR \\ 7178-CNRS/IN2P3 et ULP, Strasbourg, France
}

The aim of this study was to evaluate the ability of a prototype intraoperative mini $\gamma$-camera, the CarollReS, with a $50 \times 50 \mathrm{~mm}$ field of view, to precisely localize sentinel lymph nodes (SLNs) and to determine their depth in a series of patients with infiltrative breast cancer requiring SLN excision. Methods: With the use of phantoms, the broadness of the signal of an acquired projection was shown to linearly depend on its distance from the collimator. A preclinical ex vivo study of 25 excised SLNs demonstrated that SLN size did not influence depth estimation. The minimum activity threshold for successful use of the proposed method was determined. After a preoperative radioisotope injection and lymphoscintigraphy, the SLN was localized in a series of 11 patients using both the mini $\gamma$-camera and a $\gamma$-probe. During surgery, a ruler was used to measure the depth of all SLNs before their excision. Results: Using the measured linear dependence of image broadness, we found that the expected SLN anatomic depth was compatible with its measured depth during surgery. Conclusion: This study showed that the mini $\gamma$-camera efficiently estimated the location of SLNs in 3 dimensions.

Key Words: breast cancer; lymphoscintigraphy; intraoperative gamma-camera; sentinel lymph node; CarollReS

J Nucl Med 2007; 48:623-629

DOI: 10.2967/jnumed.106.036574

M ost types of lymphophile cancers require assessment of regional lymph nodes for staging the tumor, determining prognosis, and devising therapeutic strategies. Complete lymph node dissections are frequently associated with significant morbidity. Combining diagnostic advantages with decreased morbidity $(1,2)$, the sentinel lymph node (SLN) procedure represents one of the most recent advances in surgical oncology. It consists of the identification and

Received Jun. 26, 2006; revision accepted Dec. 6, 2006.

For correspondence or reprints contact: Carole Mathelin, MD, PhD, Service de Gynécologie-Obstétrique, Hôpital Civil, CHRU, 1 place de l'Hôpital, 67091 Strasbourg Cedex, France.

E-mail: carole.mathelin@chru-strasbourg.fr

COPYRIGHT (c) 2007 by the Society of Nuclear Medicine, Inc. removal of SLNs, which are lymph nodes that receive lymphatic drainage directly from the primary tumor. The SLN procedure is now a widely accepted method of lymph node staging for selected cases of invasive breast cancer $(3,4)$ and cutaneous melanoma (5). The concept is also being evaluated in numerous other types of cancer, including pelvic gynecologic (vulval, cervical, and endometrial) (6-9), prostate (10), colon (11), gastric (12) and thyroid (13) cancer. In all cases, successful adaptation of the SLN procedure implies that the operator has a high identification rate and a low false-negative rate. For SLN identification, in addition to the peroperative injection of a blue dye, a ${ }^{99 m}$ Tc-radiomarked colloidal solution is generally injected the day before or the day of the surgery and 2 planar scintigraphic images are taken in a nuclear medicine department. In a recent metaanalysis (14) including 69 trials and 8,059 patients with low-risk breast cancer, the proportion of patients with successfully mapped SLNs ranged from $41 \%$ to $100 \%$, with more than $50 \%$ of the studies reporting a rate under $90 \%$. The false-negative rate ranged from $0 \%$ to $29 \%$, averaging $7.3 \%$ overall. Significant inverse correlations were observed between the false-negative rate and the proportion of patients with successfully mapped SLNs $(r=-0.32 ; P=0.009)$.

Another recent study compared preoperative lymphoscintigraphy and intraoperative $\gamma$-probe detection in a series of 823 breast cancer patients who underwent the SLN procedure based on lymphoscintigraphy and blue dye, followed by complete axillary dissection. Preoperative lymphoscintigraphy revealed the SLN in $72 \%$ of the 823 patients imaged. In this case, the SLN was identified intraoperatively in $98 \%$ of patients using an intraoperative probe and blue dye, with a false-negative rate of 7\%. Of patients for whom the SLN had not been visualized on preoperative lymphoscintigraphy, the SLN was identified during surgery in $90 \%$, with the same false-negative rate of $7 \%$ (15).

However, even though SLNs can successfully be identified in most patients for whom the SLN is not visualized on 
A

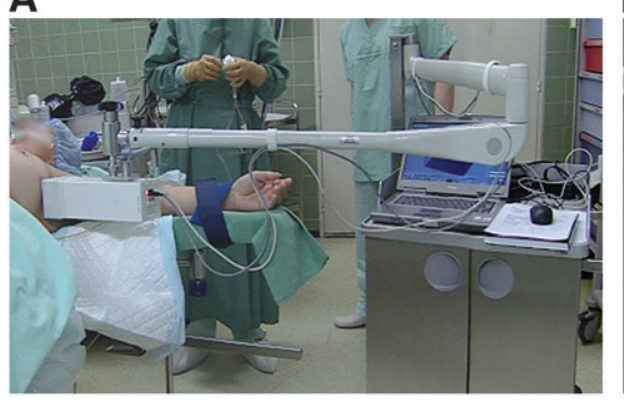

B

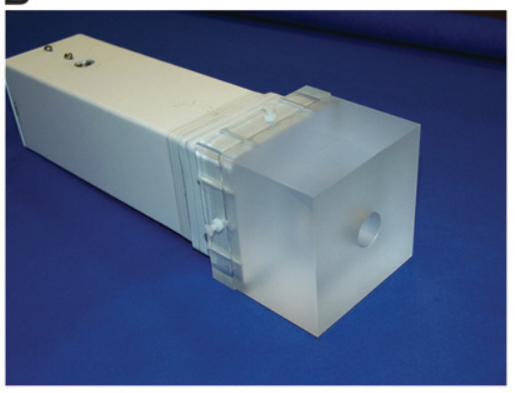

FIGURE 1. Photographs of intraoperative mini $\gamma$-camera $(A)$ and of the clear acrylic blocks placed for preclinical study of SLN depth (B). its associated electronics (18). The main characteristics of this device are given in Table 1 . The measured intrinsic spatial resolution is $3 \mathrm{~mm}$, and the spatial resolution is $10 \mathrm{~mm}$ for a source located $30 \mathrm{~mm}$ from the entrance of the collimator. The energy resolution is $45 \%$ of the full width at half maximum (FWHM), at $122 \mathrm{keV}$ (17).

Taking into account the geometric efficiency of the collimator $\left(2.3 \times 10^{-3}\right)$ and the $85 \%$ conversion probability of the 2 -mmthick scintillating crystal, the sensitivity of the mini $\gamma$-camera is equal to $1 \mathrm{cps} \cdot \mathrm{kBq}^{-1}$ for the ${ }^{99 \mathrm{~m}} \mathrm{Tc} 140-\mathrm{keV} \gamma$-ray.

\section{Scintigraphic Method}

To image an SLN at a known distance, we designed a phantom consisting of an acrylic glass block $\left(95 \times 95 \times 60 \mathrm{~mm}^{3}\right)$ with a centered hole $27 \mathrm{~mm}$ in diameter and $28 \mathrm{~mm}$ in length. This device was positioned in front of the $\gamma$-camera to center the hole in the FOV (Fig. 1B). Immediately after resection of the SLN, it was inserted into this hole and data were acquired for $2 \mathrm{~min}$ to image the isolated SLN at the bottom of the hole. The SLN dimensions were measured by the pathologist before examination of frozen sections.

\section{Patients and SLN Method}

Eleven patients with infiltrative breast cancer (diagnosed preoperatively by core biopsy) and a mean age of 55 y (range, 39-72 y) were enrolled in the study (19). The patients had no prior chemotherapy, locoregional radiotherapy, or prevalent axillary lymph node, and all patients gave informed consent.

The SLN procedure was initiated the day before surgery using a preoperative $0.1-\mathrm{mL}$ intradermal injection of rhenium sulfur (19-24 MBq of colloidal ${ }^{99 m} \mathrm{Tc}$, Nanocis; Oris) at the 4 cardinal points in the subareolar region. Lymphoscintigraphy with a conventional $\gamma$-camera (anterior and $45^{\circ}$ oblique views) was performed in the nuclear medicine department $3 \mathrm{~h}$ after the injections. The patient was on the radiologic bed, with the arm in abduction at $90^{\circ}$.

Afterward, the axillary area was explored a second time using the mini $\gamma$-camera. Because of its $50 \times 50 \mathrm{~mm}^{2} \mathrm{FOV}, 4$ images were required to map the entire axillary area $\left(100 \times 100 \mathrm{~mm}^{2}\right)$

TABLE 1

Main Characteristics of Mini $\gamma$-Camera Prototype parallel collimator, a thin cerium-doped gadolinium orthosilicate $\left(\mathrm{Gd}_{2} \mathrm{SiO}_{5}: \mathrm{Ce}\right)$ scintillating crystal (Hitachi Chemical Co. Ltd.), and an H8500 multianode photomultiplier tube (Hamamatsu) and

\section{Materials}

A detailed technical description of the mini $\gamma$-camera has been published previously (17). Figure 1A shows how the device is used in the surgical room. The device is based on the use of a lead

\begin{tabular}{|c|c|c|c|c|c|c|c|c|c|}
\hline \multicolumn{4}{|c|}{ Generalities } & \multicolumn{3}{|c|}{ Lead parallel collimator } & \multicolumn{3}{|c|}{$\begin{array}{c}\text { Inorganic scintillating crystal } \\
\text { (cerium-doped gadolinium } \\
\text { orthosilicate) }\end{array}$} \\
\hline $\begin{array}{l}\text { Total } \\
\text { weight } \\
\text { (g) }\end{array}$ & $\begin{array}{l}\text { Total } \\
\text { volume } \\
(\mathrm{mm})\end{array}$ & $\begin{array}{l}\text { FOV } \\
(\mathrm{mm})\end{array}$ & $\begin{array}{c}\text { Detection efficiency } \\
\text { 140-keV } \gamma \text {-rays } \\
\left(\mathrm{cps} \cdot \mathrm{kBq}^{-1}\right)\end{array}$ & $\begin{array}{l}\text { Thickness } \\
(\mathrm{mm})\end{array}$ & $\begin{array}{c}\text { Hole } \\
\text { diameter } \\
(\mathrm{mm})\end{array}$ & $\begin{array}{l}\text { Septa } \\
(\mathrm{mm})\end{array}$ & $\begin{array}{l}\text { Density } \\
\left(\mathrm{g} \cdot \mathrm{cm}^{-3}\right)\end{array}$ & $\begin{array}{l}\text { Decay } \\
\text { time } \\
\text { (ns) }\end{array}$ & $\begin{array}{l}\text { Thickness } \\
(\mathrm{mm})\end{array}$ \\
\hline 2,490 & $78 \times 78 \times 275$ & $50 \times 50$ & 1.0 & 10.0 & 2.0 & 0.2 & 6.71 & 40 & 2.0 \\
\hline
\end{tabular}



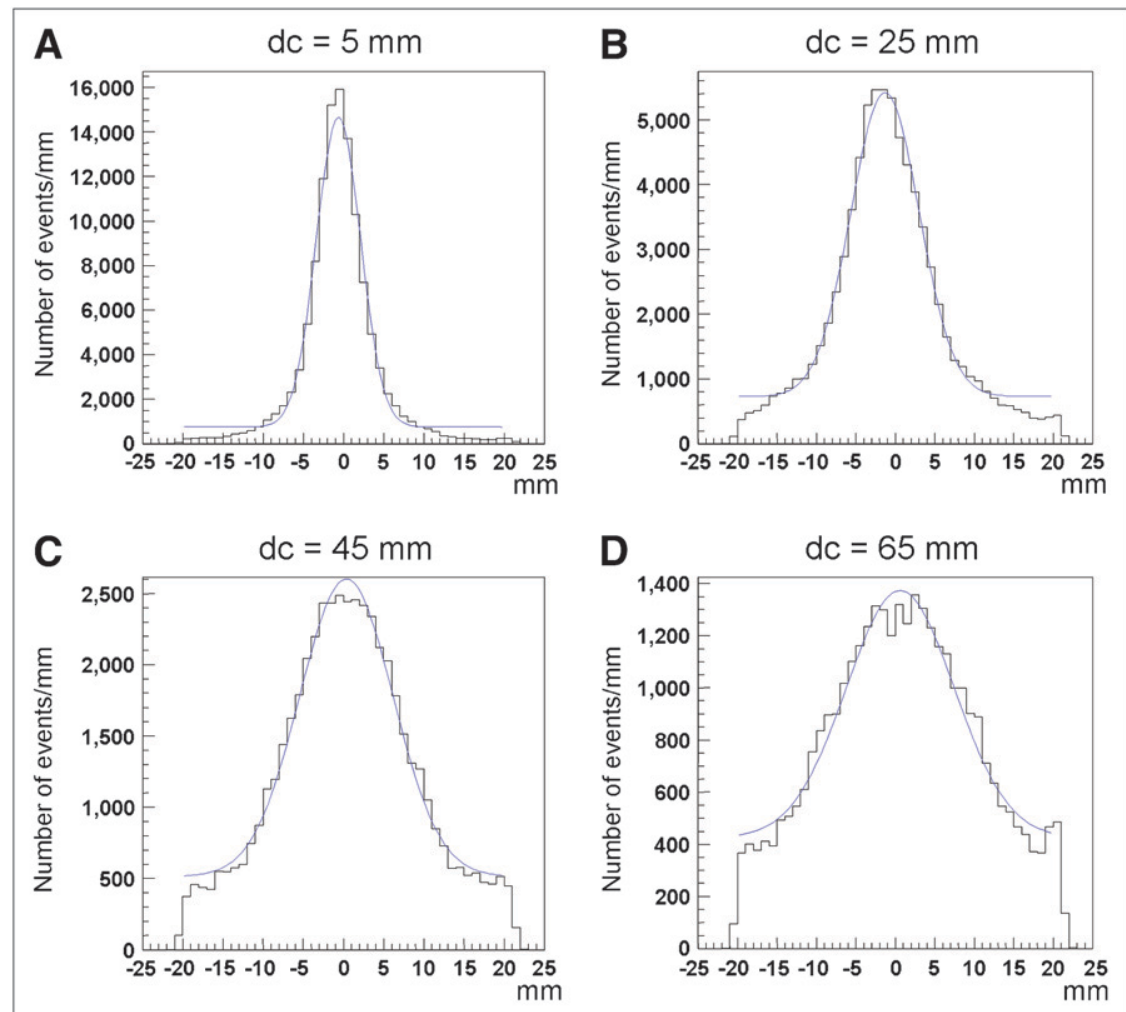

FIGURE 2. Profiles on 1 coordinate axis of image of $35.7-\mathrm{kBq}{ }^{57} \mathrm{Co}$ pointlike source at 4 collimator distances $\left(\mathrm{d}_{\mathrm{c}}=5\right.$, 25, 45, and $65 \mathrm{~mm}$ ). Data are fitted by sum of constant and gaussian function (superimposed curve).

with the patient in the operative position (the arm in abduction at $80^{\circ}$ ). Data acquisition for each image required $2 \mathrm{~min}$.

During surgery, the SLN was located with the aid of the CarolIReS intraoperative probe (20), and its depth was measured using a surgical ruler (Aspen Surgical) before resection. The depth was defined as the perpendicular distance from the center of the SLN to the skin surface, with an estimated error of $5 \mathrm{~mm}$. The activity of the SLN was measured using a $\gamma$-counter immediately after its resection (20), and standard frozen sections were then prepared for histopathologic analysis. The axillary node was completely cleared only if the SLN had metastatic involvement.

\section{RESULTS}

The initial studies were performed using 5 phantoms with activities ranging from 10 to $36 \mathrm{kBq}$ of ${ }^{57} \mathrm{Co}(122-\mathrm{keV}$ $\gamma$-rays) to test the validity of the method. These phantoms were positioned at 7 distances $\left(\mathrm{d}_{\mathrm{c}}\right)$ from the collimator by putting various numbers of 10 -mm-thick clear acrylic plates in front of the mini $\gamma$-camera. Clear acrylic plates were chosen to simulate the diffusion of $\gamma$-rays in human tissue. The $x$ - and $y$-coordinates of the interaction point of the $\gamma$-ray in the crystal were calculated as the center of gravity of the fired multianode photomultiplier tube cells (17). For each distance $\mathrm{d}_{\mathrm{c}}, 2$ profiles were obtained by integrating the data in both directions ( $x$ and $y$ ). Each profile was fitted by the sum of a constant value representing the flat background contribution and a gaussian curve as illustrated in Figure 2 for 4 different distances. The variation in the FWHM (calculated using the SD of the gaussian distribution) in both profiles is presented in Figure 3, as

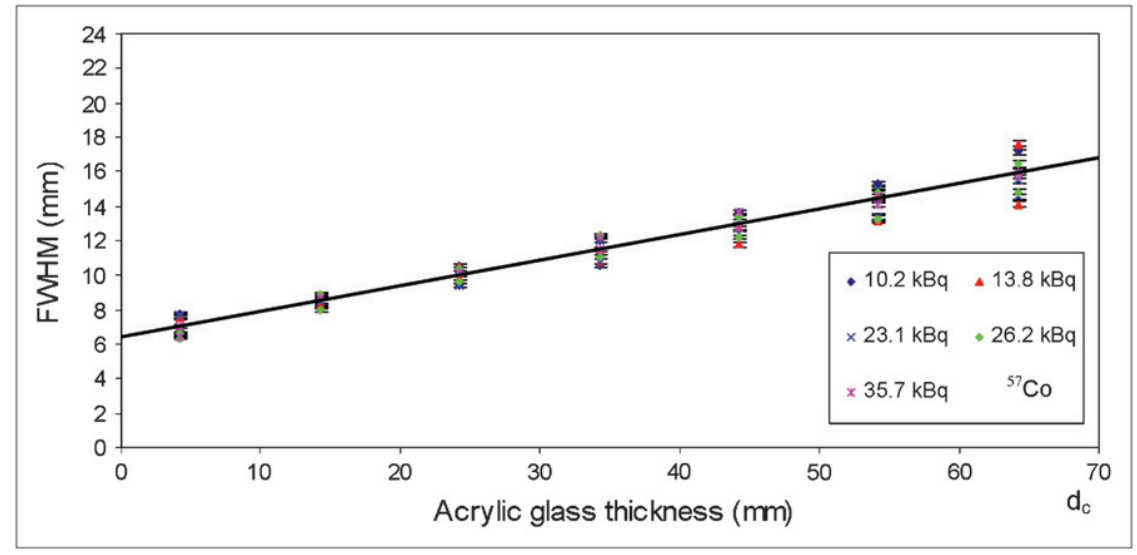

FIGURE 3. Linear variation of FWHM (obtained by fitting procedure defined in Fig. 2) vs. distance $d_{c}$, from collimator, of 5 different activity pointlike ${ }^{57}$ Co sources. 

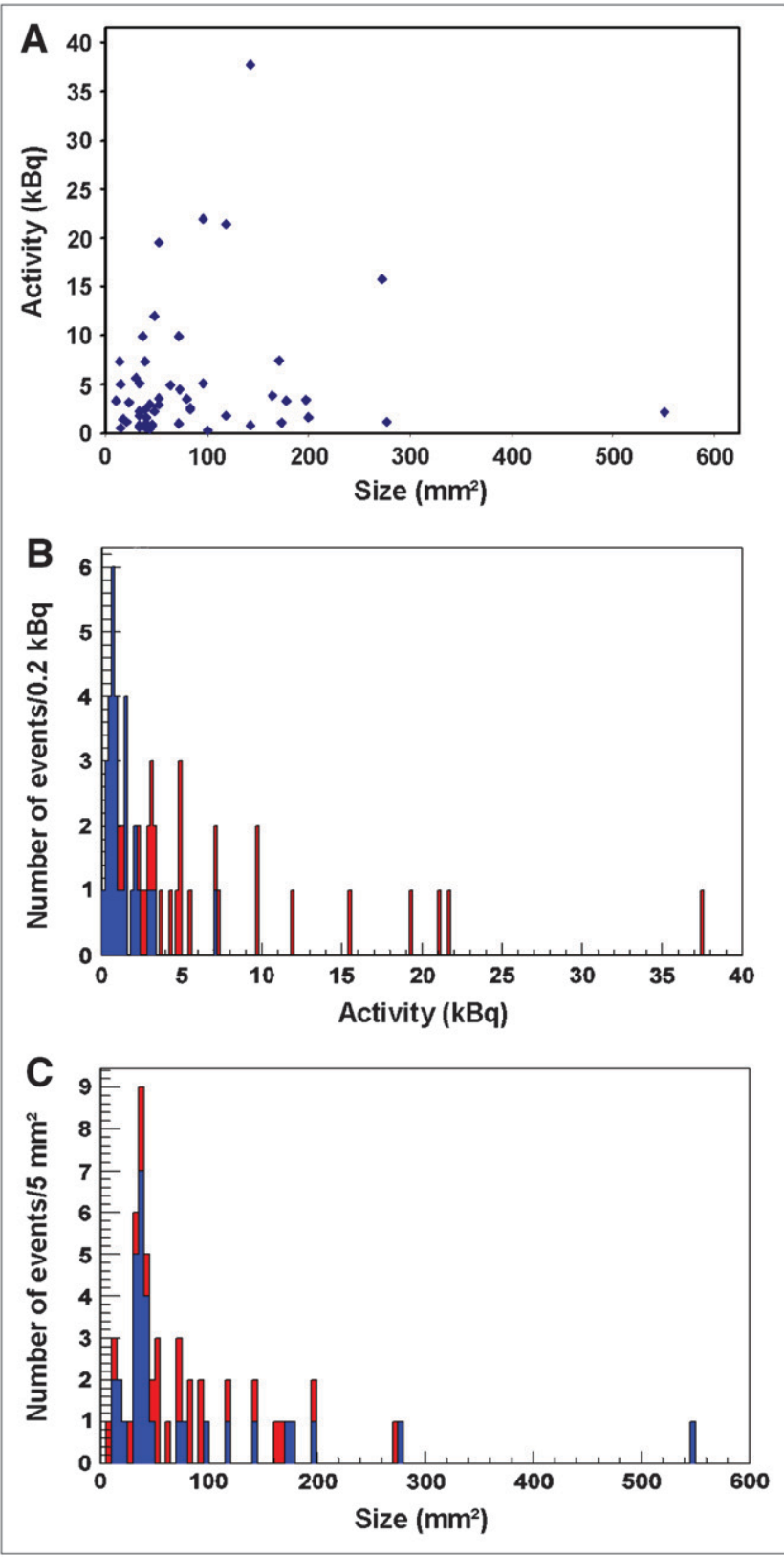

FIGURE 4. (A) Plot of activity vs. size for ex vivo measurements of 56 SLNs. (B and C) Distribution of activity (B) and size (C) for sample of 56 SLNs with successful (red) and unsuccessful (blue) determination of their depth.

well as the least squared fit of a straight line. The relationship between the FWHM and the distance $\mathrm{d}_{\mathrm{c}}$, where the $x$ and $y$ data are combined, is given by FWHM $(\mathrm{mm})=(0.15 \pm$ $0.02) \cdot \mathrm{d}_{\mathrm{c}}(\mathrm{mm})+(6.5 \pm 0.5 \mathrm{~mm})$, with an $r$ value of 0.98 . As expected, the relationship did not depend on the phantom activity and was on the order of $1.5 \mathrm{~mm}$ per $10 \mathrm{~mm}$ of distance from the collimator, with an offset of $6.5 \mathrm{~mm}$, which is the spatial resolution of the system for a $d_{c}$ of $0 \mathrm{~mm}$.

\section{Preclinical Study}

This study was performed to evaluate the effects of SLN size and activity on the determination of its depth. The method was applied to a sample of 56 fresh SLNs positioned $32 \mathrm{~mm}$ from the collimator at the bottom of the hole of the device (Fig. 1B). The SLN size $((\pi \cdot$ long axis.short axis)/4) is given as the ellipsoidal cross-section surface in square millimeters calculated with the 2 measured axes (12.4 $\pm 6.5 \mathrm{~mm}$ and $7.4 \pm 3.6 \mathrm{~mm}$ on average for the long axis and the short axis, respectively). SLN activity and size did not correlate, as is shown in Figure 4A $(r=0.12)$. Figures $4 \mathrm{~B}$ and $4 \mathrm{C}$ present the distributions of the measured activity and the size of the 56 SLN samples. No correlation was found between the FWHM calculated from the profiles and the SLN size $(r=0.09)$. In other words, it was impossible to extract a contribution to the width of the profiles coming from a distribution of the radioactivity inside the SLN. The estimated distance $d_{p}$ obtained by the method defined by the phantom study is shown in Figure 5. This was possible only for a subsample of 25 SLNs (23 for both profiles and 2 for one profile only). The data gave a gaussian curve with mean values of $39.9 \mathrm{~mm}$ for $\mathrm{d}_{\mathrm{p}}$ and $11.5 \mathrm{~mm}$ for $\sigma_{\mathrm{dp}}$. The predicted distance $\mathrm{d}_{\mathrm{p}}$ appears an overestimation, compared with the experimentally fixed value of $32 \mathrm{~mm}$. Taking into account the $10-\mathrm{mm}$ mean value of 2 SLN axis lengths, this result is compatible with the distance from the SLN center to the collimator. The red part of Figures $4 \mathrm{~B}$ and $4 \mathrm{C}$ represents, respectively, the activity and the size of the 25-SLN subsample. At SLN activity values below $2 \mathrm{kBq}$ (Fig. 4B), the calculation fails mainly because of a poor signal-to-noise ratio. Above a $2-\mathrm{kBq}$ activity threshold, the efficiency of the method is evaluated to be $86 \% \pm 23 \%$, independent of the SLN size (Fig. 4C).

\section{Clinical Study}

The final analysis of the removed breast lesions revealed an infiltrative ductal carcinoma in 7 cases and an infiltrative lobular carcinoma in 4 cases, with an average size of $15 \mathrm{~mm}$ (range, 2-27 mm). Fourteen SLNs were detected

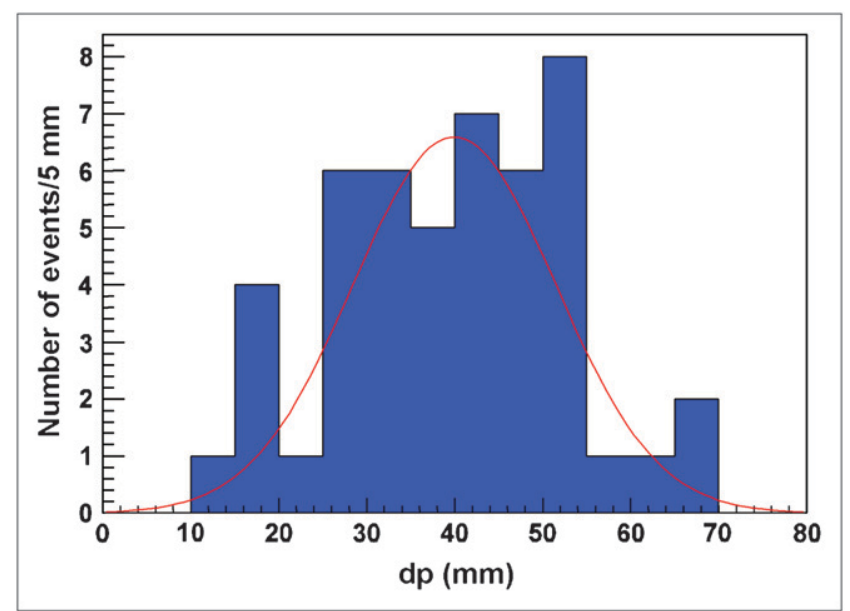

FIGURE 5. Distribution of estimated distance $d_{p}$ between SLN and collimator for subsample of 25 SLNs. Data are fitted by gaussian function (superimposed curve). 
by conventional lymphoscintigraphy and 16 by the mini $\gamma$-camera. The complete SLN procedure allowed the detection of 20 SLNs with a mean of 1.8 (range, 1-3) per patient. Four involved SLNs were detected in 3 patients who subsequently underwent complete axillary clearance (Table 2).

Figure 6 compares a conventional lymphoscintigraphy image with an image from the mini $\gamma$-camera.

The linear dependence of the FWHM on the source distance was applied to data obtained with the mini $\gamma$-camera. By measuring the broadness of the image, which depends on the distance of the SLN from the collimator entrance, we could predict the depth of the SLN in the axillary area. The results concerning the expected depth (given, respectively, by the $x$ and $y$ profiles) of 12 SLNs are summarized in Table 2. Because the required information was not fully contained in the $50 \times 50 \mathrm{~mm}^{2}$ FOV of the current prototype of the mini $\gamma$-camera, our technique could not be applied to the total imaged sample of SLNs. For 4 of them, the information required to obtain useful profiles was only partially contained in the image (at a corner of the FOV). When a difference existed between the 2 expected depths, the mean value was used to determine the correlation between the predicted $\left(\mathrm{d}_{\mathrm{p}} \pm 11.5 \mathrm{~mm}\right)$ and the measured $\left(\mathrm{d}_{\mathrm{m}} \pm 5 \mathrm{~mm}\right)$ SLN depths, as presented in Figure 7. A straight line fit gives the following result: $d_{p}$ $(\mathrm{mm})=(0.5 \pm 0.2) \cdot \mathrm{d}_{\mathrm{m}}(\mathrm{mm})+(24 \pm 9 \mathrm{~mm})$, with an $r$ value of 0.76 .

\section{DISCUSSION}

In our clinical series, the proportion of patients with successfully mapped SLNs was $64 \%$ (7/11). In 4 cases, conventional lymphoscintigraphy did not show the totality of the SLNs. Only 14 of 20 SLNs were visualized on conventional lymphoscintigraphy ( $70 \%$ efficiency). On the day of the injection, use of the mini $\gamma$-camera allowed detection of 2 additional SLNs. In 3 cases, the total number of SLNs was not detected preoperatively by conventional lymphoscintigraphy or by the mini $\gamma$-camera. There are probably several explanations. First, the pictures were obtained the day before surgery, and lymphatic drainage had perhaps not been completed. In some cases, SLNs were too closely situated for the spatial resolution of the imaging device. The low SLN detection efficiency of the mini $\gamma$-camera $(80 \%)$ could also be explained by the limited FOV. The 4 data acquisitions obtained by moving the mini $\gamma$-camera did not ensure that the entire axillary area was covered (it was difficult to take precisely consecutive and joint images to obtain the $100 \times 100 \mathrm{~mm}^{2}$ full image).

Our preclinical study demonstrated that SLN depth was estimated efficiently only when the SLN activity was greater than $2 \mathrm{kBq}$ for a 2-min data acquisition. This limitation is significant if the images are to be obtained just

TABLE 2

Summary of Patient Characteristics and SLN Analysis (Size, Activity, Depth, Pathologic Analysis)

\begin{tabular}{|c|c|c|c|c|c|c|c|c|c|c|c|c|}
\hline $\begin{array}{c}\text { Patient } \\
\text { no. }\end{array}$ & $\begin{array}{l}\text { Age } \\
\text { (y) }\end{array}$ & $\begin{array}{l}\text { Cancer } \\
\text { type }\end{array}$ & $\begin{array}{l}\text { Tumor } \\
\text { size } \\
\text { (mm) }\end{array}$ & $\begin{array}{l}\text { Injected } \\
\text { dose } \\
\text { (MBq) }\end{array}$ & $\begin{array}{c}\text { Conventional } \\
\gamma \text {-camera } \\
\text { SLN }(n)\end{array}$ & $\begin{array}{c}\text { Mini } \\
\gamma \text {-camera } \\
\text { SLN }(n)\end{array}$ & $\begin{array}{l}\text { Surgery } \\
\text { SLN } \\
(n)\end{array}$ & $\begin{array}{l}\text { SLN } \\
\text { size } \\
(\mathrm{mm})\end{array}$ & $\begin{array}{c}\text { SLN } \\
\text { activity } \\
(\mathrm{kBq})^{*}\end{array}$ & $\begin{array}{l}\text { Camera } \\
\text { depth } \\
(\mathrm{mm})^{\dagger}\end{array}$ & $\begin{array}{l}\text { Surgery } \\
\text { depth } \\
(\mathrm{mm})^{\ddagger}\end{array}$ & $\begin{array}{c}\text { Pathologic } \\
\text { analysis }^{\S}\end{array}$ \\
\hline \multirow[t]{2}{*}{1} & \multirow[t]{2}{*}{66} & \multirow[t]{2}{*}{ Ductal } & \multirow[t]{2}{*}{11} & \multirow[t]{2}{*}{24} & \multirow[t]{2}{*}{2} & \multirow[t]{2}{*}{2} & \multirow[t]{2}{*}{2} & $15 \times 10$ & 65 & $23-47$ & 45 & pNO \\
\hline & & & & & & & & $10 \times 4$ & 19 & $34-50$ & 55 & pNO \\
\hline 2 & 68 & Ductal & 2 & 20 & 1 & 1 & 1 & $15 \times 10$ & 26 & $26-45$ & 45 & pNO \\
\hline \multirow[t]{2}{*}{3} & \multirow[t]{2}{*}{40} & \multirow[t]{2}{*}{ Ductal } & \multirow[t]{2}{*}{10} & \multirow[t]{2}{*}{24} & \multirow[t]{2}{*}{1} & \multirow[t]{2}{*}{1} & \multirow[t]{2}{*}{2} & $17 \times 12$ & 44 & 33-59 & 15 & pNO \\
\hline & & & & & & & & $10 \times 6$ & 8 & - & 20 & pNO \\
\hline \multirow[t]{2}{*}{4} & \multirow[t]{2}{*}{50} & \multirow[t]{2}{*}{ Ductal } & \multirow[t]{2}{*}{27} & \multirow[t]{2}{*}{21} & \multirow[t]{2}{*}{2} & \multirow[t]{2}{*}{2} & \multirow[t]{2}{*}{2} & $10 \times 5$ & 6 & $32-36$ & 25 & pNO \\
\hline & & & & & & & & $15 \times 8$ & 20 & - & 20 & pN1 \\
\hline \multirow[t]{3}{*}{5} & \multirow[t]{3}{*}{68} & \multirow[t]{3}{*}{ Lobular } & \multirow[t]{3}{*}{26} & \multirow[t]{3}{*}{24} & \multirow[t]{3}{*}{2} & \multirow[t]{3}{*}{2} & \multirow[t]{3}{*}{3} & $10 \times 5$ & 30 & $36-78$ & 50 & pNO \\
\hline & & & & & & & & $25 \times 15$ & 30 & - & 35 & pN1 \\
\hline & & & & & & & & $10 \times 5$ & 22 & - & 35 & pNO \\
\hline 6 & 51 & Lobular & 15 & 24 & 1 & 2 & 3 & $15 \times 8$ & 38 & $20-45$ & 35 & pNO \\
\hline & & & & & & & & $10 \times 4$ & 31 & - & 20 & pNO \\
\hline & & & & & & & & $16 \times 10$ & 28 & - & 20 & pNO \\
\hline 7 & 47 & Ductal & 10 & 24 & 1 & 1 & 1 & $25 \times 16$ & 55 & $36-42$ & 35 & pNO \\
\hline 8 & 45 & Ductal & 12 & 24 & 1 & 1 & 1 & $20 \times 20$ & 70 & $62-67$ & 75 & pNO \\
\hline 9 & 72 & Ductal & 15 & 24 & 1 & 1 & 1 & $15 \times 15$ & 124 & $56-56$ & 55 & pNO \\
\hline 10 & 39 & Lobular & 15 & 24 & 1 & 1 & 1 & $18 \times 10$ & 44 & $52-56$ & 55 & pNO \\
\hline & & & & & & & & $10 \times 6$ & 47 & $58-75$ & 85 & pN1 \\
\hline 11 & 58 & Lobular & 24 & 19 & 1 & 2 & 3 & $20 \times 12$ & 5 & - & 60 & pN1 \\
\hline & & & & & & & & $6 \times 4$ & 4 & - & 40 & pNO \\
\hline
\end{tabular}

${ }^{*}$ Estimation of remaining activity of SLN taking into account geometric detection efficiency of $\gamma$-counter.

${ }^{\dagger}$ Estimation of SLN depth using information given by FWHM of fitted gaussian curves on mini $\gamma$-camera image profiles. $(-\quad=$ immeasurable because required information was not fully contained in $50 \times 50 \mathrm{~mm}^{2} \mathrm{FOV}$ ).

${ }^{\ddagger}$ SLN depth measured with ruler during surgery.

§Union Internationale Contre le Cancer classification pTNM. 


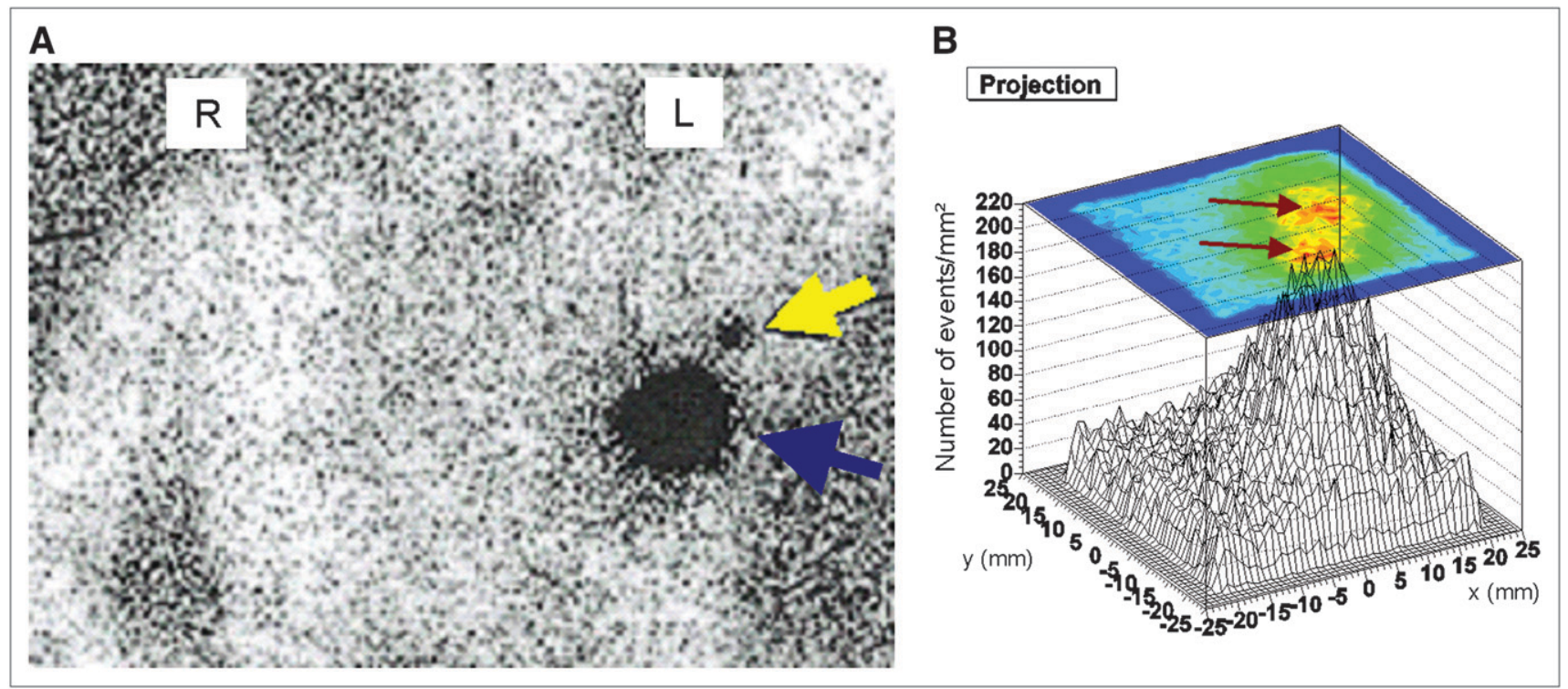

FIGURE 6. (A) Anterior view of conventional lymphoscintigraphy. Yellow arrow indicates SLN. Blue one indicates subareolar injection site. (B) For same patient, mini $\gamma$-camera image shows 2 closer SLNs indicated by 2 arrows.

before surgery, when an injection on the order of $20 \mathrm{MBq}$ of radiocolloid takes place the day before the surgery. The efficiency of the method can be improved if the image acquired by the mini $\gamma$-camera is obtained after injection, with a time delay that has to be experimentally determined.

A new clinical trial to compare the performance of conventional lymphoscintigraphy with that of a mini $\gamma$-camera having a FOV of $100 \times 100 \mathrm{~mm}$ will begin this year. It is still too early to propose replacing conventional $\gamma$-cameras with intraoperative mini $\gamma$-cameras.

A simple comparison between probe and mini $\gamma$-camera and between conventional $\gamma$-camera and mini $\gamma$-camera in terms of sensitivity is not relevant to their classification

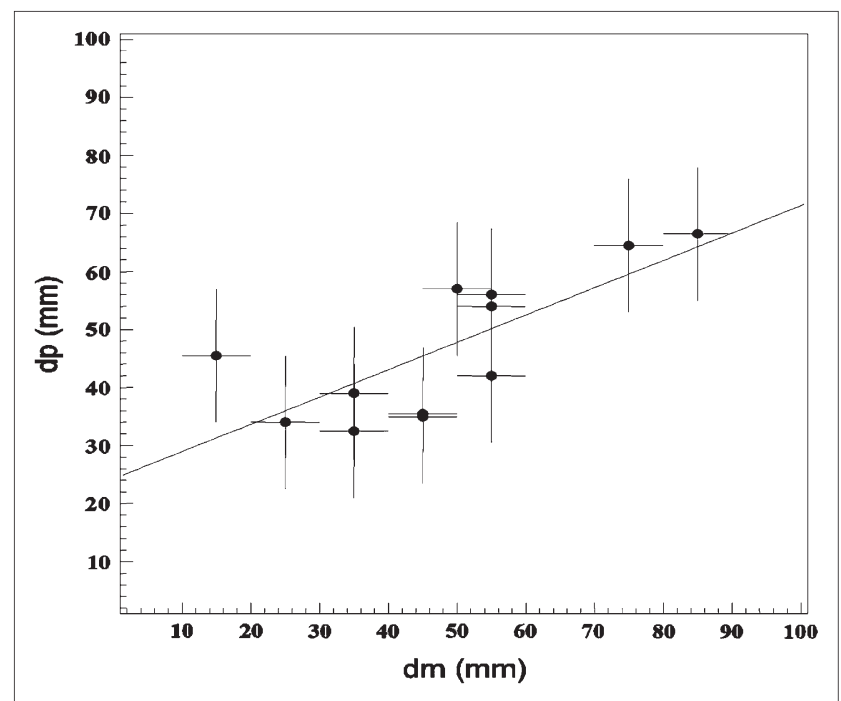

FIGURE 7. Correlation between predicted depth $d_{p}$ of SLN and its measurement $d_{m}$ by ruler during surgery. Linear squared fit to data is also represented. because of their different goals. For example, the sensitivities of the devices used in our study are 0.1, 1.0, and 10.0 cps $\cdot \mathrm{kBq}^{-1}$ for the conventional $\gamma$-camera, the mini $\gamma$-camera, and the $\gamma$-probe, respectively. In addition, those numbers have to be related to the respective FOVs: $400 \times 500,50 \times 50$, and $12 \mathrm{~mm}^{2}$. Because of the small number of patients in our series, we could not significantly demonstrate that the mini $\gamma$-camera was better than the conventional $\gamma$-camera, but the possibility of using the mini $\gamma$-camera before, during, and after surgery is a huge advantage.

Our clinical series demonstrates a strong correlation between the predicted and measured depths of SLNs. It is crucial to know the precise number of SLNs present and to locate them in 3 dimensions. This knowledge improves SLN identification, avoids the removal of other lymph nodes, and may reduce hospitalization time.

\section{CONCLUSION}

Our study showed that the mini $\gamma$-camera is well adapted to SLN localization and efficiently estimates SLN depth. With the $100 \times 100 \mathrm{~mm}^{2}$ FOV device under construction, the full axillary area will be covered, improving the efficiency of SLN detection. As a means of quality control and to help decrease the false-negative rate, a postoperative scintigraphic image can be acquired to prove that no SLNs remain after surgery.

\section{ACKNOWLEDGMENTS}

We thank Kadour Annane, Jean-Pierre Bellocq, JeanPhilippe Brettes, Marie-Pierre Chenard, Doris Frankhauser, Philippe Liégeois, Jean-Louis Mehl, and Roland Schaeffer for their collaboration and David Brasse and Shanti 
Natarajan-Amé for their helpful discussions. This work was supported by funds from the Centre National de la Recherche Scientifique, the Hôpitaux Universitaires de Strasbourg, the University Louis Pasteur, the Région Alsace, and the Pfizer Laboratory. We are indebted to the Ligue Nationale Française contre le Cancer and the Comités du Haut-Rhin et du Bas-Rhin for their constant and considerable financial support.

\section{REFERENCES}

1. Schulze T, Mucke J, Markwardt J, Schlag PM, Bembenek A. Long-term morbidity of patients with early breast cancer after sentinel lymph node biopsy compared to axillary lymph node dissection. J Surg Oncol. 2006;93: $109-119$.

2. Wilke LG, McCall LM, Posther KE, et al. Surgical complications associated with sentinel lymph node biopsy: results from a prospective international cooperative group trial. Ann Surg Oncol. 2006;13:491-500.

3. Lyman GH, Giuliano AE, Somerfield MR, et al. American Society of Clinical Oncology guideline recommendations for sentinel lymph node biopsy in earlystage breast cancer. J Clin Oncol. 2005;23:7703-7720.

4. James TA, Edge SB. Sentinel lymph node in breast cancer. Curr Opin Obstet Gynecol. 2006;18:53-58.

5. Vaquerano J, Kraybill WG, Driscoll DL, Cheney R, Kane JM III. American Joint Committee on Cancer clinical stage as a selection criterion for sentinel lymph node biopsy in thin melanoma. Ann Surg Oncol. 2006;13:198-204.

6. Zhang WJ, Zheng R, Wu LY, Li XG, Li B, Chen SZ. Clinical application of sentinel lymph node detection to early stage cervical cancer [in Chinese]. $A i$ Zheng. 2006;25:224-228.

7. Robison K, Steinhoff MM, Granai CO, Brard L, Gajewski W, Moore RG. Inguinal sentinel node dissection versus standard inguinal node dissection in patients with vulvar cancer: a comparison of the size of metastasis detected in inguinal lymph nodes. Gynecol Oncol. 2006;101:24-27.
8. Rob L, Charvata M, Robova H, et al. Sentinel lymph node identification (SLNI) in the management of conservative surgery in early cervical cancer: is it acceptable? Gynecol Oncol. 2005;99(3, suppl 1)S147-S148.

9. Carcopino X, Houvenaeghel G, Buttarelli M, Charaffe-Jauffret E, Gonzague L, Rossi I. Feasibility and morbidity of sentinel lymph node detection in patients with vulvar carcinoma [in French]. Bull Cancer. 2005;92:489-497.

10. Petros JA. Sentinel lymph node mapping in prostate cancer: opportunities remain to identify truly positive nodes. J Urol. 2006;175:421-422.

11. Saha S, Seghal R, Patel M, et al. A multicenter trial of sentinel lymph node mapping in colorectal cancer: prognostic implications for nodal staging and recurrence. Am J Surg. 2006;191:305-310.

12. Mochiki E, Kuwano H, Kamiyama Y, et al. Sentinel lymph node mapping with technetium-99m colloidal rhenium sulfide in patients with gastric carcinoma. Am J Surg. 2006;191:465-469.

13. Pelizzo MR, Merante Boschin I, Piotto A, et al. Sentinel lymph node procedure in thyroid carcinoma patients: our experience. Minerva Chir. 2006;61:25-29.

14. Kim T, Giuliano AE, Lyman GH. Lymphatic mapping and sentinel lymph node biopsy in early-stage breast carcinoma: a metaanalysis. Cancer. 2006;106:4-16.

15. Goyal A, Newcombe RG, Mansel RE, et al. Role of routine preoperative lymphoscintigraphy in sentinel node biopsy for breast cancer. Eur J Cancer. 2005;41:238-243.

16. Kim SC, Kim DW, Moadel RM, et al. Using the intraoperative hand held probe without lymphoscintigraphy or using only dye correlates with higher sensory morbidity following sentinel lymph node biopsy in breast cancer: a review of the literature. World J Surg Oncol. 2005;3:64.

17. Piqueras I, Gizard B, Huss D, Brasse D, Mathelin C, Guyonnet J. A new mini gamma camera for sentinel lymph node identification in patients with breast cancer. In: Proceedings of SCINT 2005 (International conference on inorganic scintillators and their industrial application); September 19-23, 2005; Alushta, Ukraine.

18. Bard P, Avner S, Bekaert V, et al. Electronics dedicated to multi-anode photomultiplier tubes for imaging scintigraphic devices. In: Proceedings of the 14th IEEE-NPSS Real Time Conference; 2005; Stockholm, Sweden.

19. ClinicalTrials.gov Web site (a service of the U.S. National Institutes of Health). Available at: http://www.clinicaltrials.gov/ct/show/NCT00357487; jsessionid= 1B2EA82778105 B140C998A953959497?order=29. Accessed January 29, 2007

20. Mathelin C, Piqueras I, Guyonnet JL. Performances of a new prototype handheld scintillating probe for the search of sentinel lymph nodes in breast cancer. Eur J Surg Oncol. 2006;32:24-28. 